\title{
A Multiple Criteria Decision Support Web-Based System for Sustainable Urban Development
}

\author{
E.K.Zavadskas, A.Kaklauskas, P.Vainiunas, J.Saparauskas, S.Raslanas, M.Gikys \\ Vilnius Gediminas Technical University, Sauletekio al. 11, LT-2040 Vilnius, Lithuania. \\ property@st.vtu.lt
}

\begin{abstract}
The best sustainable urban development strategy of another country cannot just be copied. Strategies can only be adapted into a real economic, social, political, legislation/regulation and provision situation of the existing state. There is no such thing as a single sustainable urban development strategy to suit all societies and that could be applied to all countries. Based on the analysis of existing information, expert and decision support systems and in order to determine the best practice of sustainable urban development and to prepare recommendations for countries under consideration a Web-Based Sustainable Urban Development Decision Support System consisting of a database, database management system, model-base, model-base management system and user interface was developed. Studying the expertise of advanced industrial economies formed the initial database of the best practice.
\end{abstract}

KEYWORDS: Decision Support Web-Based Systems, Multiple Criteria Analysis, Sustainable Urban Development.

\section{INTRODUCTION}

Sustainable urban development is an information business. Technological innovation mainly through changes in the availability of information and communication technology inclusive calculators, analysers, software, neural networks, decision support and expert systems that have been provided by a variety of new services developed by the sustainable urban development sector. Most of all calculators, analysers, software, decision support and expert systems, neural networks seek to find out how to make the most economic sustainable urban development decisions and most of all these decisions are intended only for economic objectives. Sustainable urban development alternatives under evaluation have to be evaluated not only from the economic position, but take into consideration economic, institutional, environment, cultural, education, political, legal, social, management, technical, technological and other factors. Therefore, applying multiple criteria analysis methods and multiple criteria decision support systems may increase the efficiency of construction calculators, analysers, software, decision support and expert systems, neural networks and integrated construction on-line systems. Based on an analysis of existing the information, expert and decision support systems and in order to determine the most efficient versions Web-Based Sustainable Urban Development Decision Support System was developed by authors of paper. This system and the related questions were analysed in this paper.

\section{CALCULATORS, ANALYSERS, SOFTWARE, NEURAL NETWORKS, EXPERT AND DECISION SUPPORT SYSTEMS}

The major players in a sustainable urban development can use calculators, analyzers, software, neural networks, expert and decision support systems, etc.

A calculator is software application that is used for completing mathematical calculations. Calculators range from very cheap software, capable of performing basic arithmetical operations, to those whose capabilities extend to sophisticated mathematical and statistical manipulations and those that may be programmed with a large numbers of steps. Web sites [1, etc.] sometimes contain sustainable urban development calculators.

Interested parties also use software with various purposes as listed below: Rural/Urban Projection (RUP) Program [2]; atmospheric pollution, energy 
economics, indoor air quality, multi-building facilities, solar/climate analysis, training, utility evaluation, validation tools, ventilation/airflow and water conservation [3].

The major players in a sustainable urban development can use various purpose decision support systems. The decision support system (DSS) provides a framework through which decision-makers can obtain the necessary assistance needed for making decisions through an easy-to-use menu or command system. Generally, a DSS will provide help in formulating alternatives, accessing data, developing models and interpreting their results and by selecting options or analyzing the impacts of a selection. For example, Rylatt et al. [Rylatt] describes the development of a solar energy planning system, consisting of a methodology and decision support system for planners and energy advisers. Intended primarily to predict and realise the potential of solar energy on an urban scale, the system will support decisions in relation to the key solar technologies: solar water heating, photovoltaics and passive solar gain.

Expert systems today generally serve to relieve a 'human' professional of some of the difficult but clearly formulated tasks. For example, Onishi [Onishi] developed an expert system FGMS200 for integrated global modeling. The FGMS200 has been developed as a media of providing global information to the human society and finding out possibilities of policy coordination among countries in order to achieve sustainable development of the world economy.

Neural network is a method of computing that tries to copy the way the human brain works. A group of processing elements receives data and at the same time links are made between the elements, as the repeated patterns are recognized. A GIS-RDBMS-Neural Network-based system has been used for on-line consequence analysis of regional developmental proposals. The model outputs are used as the indicators of sustainable development [Khanna]. The feed forward neural networks have been used for hydrological modelling of run-off in Himalayan glacier basins [Buch]. Similar efforts in forecasting include river flow forecasting [Ichikawaet], and demand for electric power [Yuan]. Artificial neural networks have also been used as cognitive maps, e.g. in the application of aesthetic design of dam structures [Furuta]. The other important area of application is in the development of control systems for water and wastewater treatment plants [Cote].

\section{DECISION SUPPORT SYSTEM AS DEVELOPED BY THE AUTHORS}

Based on the analysis of existing information, neural networks, expert and decision support systems and in order to determine best practice of sustainable urban development and to prepare recommendations for countries under consideration a Sustainable Urban Development Decision Support System (SUD-DSS) consisting of a database, database management system, model-base, model-base management system and user interface was developed.

\subsection{Initial Database of the Best Practice}

The database of the best practice usually is formed by studying the expertise of advanced industrial economies. Simulation can be undertaken to provide insight into creating an effective database of the best practices: social cohesion (ecologically sound, economically efficient and socially cohesive settlements, caring society, no poverty); quality of life (more comfort, time, money; happy people, more pleasure, less work, reconstruction of settlement structure, revitalisation of street spaces, confidence); environment (a peaceful, cultural society; safe, pollution free, green environment; surroundings, public transport); economy (full employment, innovative); knowledge society (user driven integrated tools, equal access, e-democratisation); decision making (cooperation between authorities, access to information, participation, subsidiarity, assessment tools); safety/security; etc.

A thorough sustainable urban development evaluation is quite difficult to undertake, because a city and its environment are complex system (compatible with political, economic, social, cultural, institutional, technological, environmental, legal/regulatory, education situation, etc.) where all sub-systems influence the total efficiency performance and where the interdependence between sub-systems play a significant role.

Sustainable urban development involves a number of interested parties who pursue various goals and have different potentialities, educational levels and experiences. This leads to various approaches of the above parties to decision-making in this field. In order to do a full analysis of the available alternatives and to obtain an efficient compromise solution, it is often necessary to analyse economic, institutional, environment, cultural, education, political, legal, social, management, technical, 
technological and other type of information. This information should be provided in a user-oriented way.

The presentation of information needed for decision-making in the SUD-DSS may be in a conceptual form (i.e. digital/numerical, textual, graphical, diagrams, graphs and drawing, etc), photographic, sound, video and quantitative forms. The presentation of quantitative information involves criteria systems and subsystems, units of measurement, values and initial weights that fully define the provided variants. Conceptual information means a conceptual description of the alternative solutions, the criteria and ways of determining their values and the weights, etc.

In this way, the SUD-DSS enables the decisionmaker to receive various conceptual and quantitative information on sustainable urban development from a database and a model-base allowing him/her to analyse the above factors and to form an efficient solution.

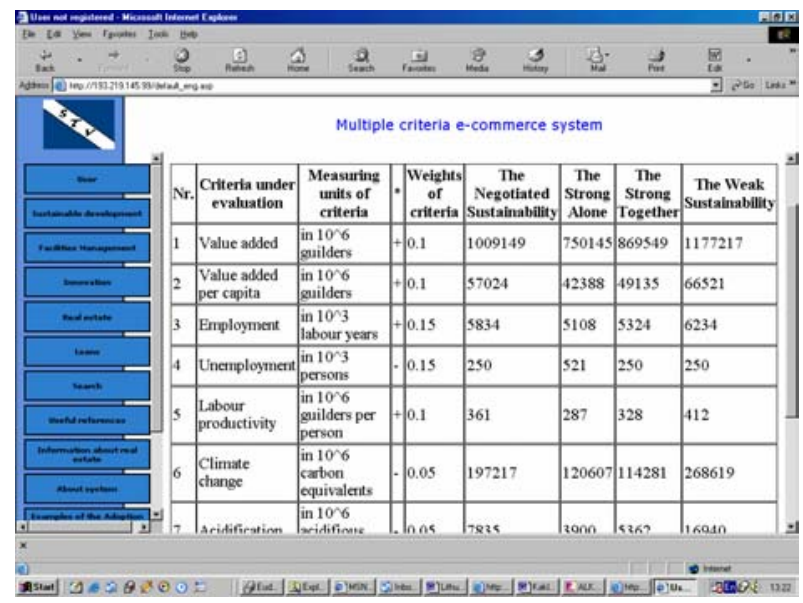

Figure 1. Initial data for integrated assessment for sustainable economic structures

The following tables form the SUD-DSS's database:

- Initial data tables. These contain conceptual information about sustainable urban development alternatives.

- Tables assessing sustainable urban development solutions. These contain quantitative information about alternative sustainable urban development solutions: integrated assessment for sustainability appraisal in cities and regions, sustainable economic structures (see Fig. 1), carryingcapacity as a basis for sustainable development, etc.
To design the structure of a database and perform its completion, storage, editing, navigation, searching and browsing etc. a database management system was used in this research.

The user seeking for an efficient sustainable urban development solution should provide, in the tables assessing sustainable urban development solutions, the exact information about alternatives under consideration as to the city's financial situation. It should be noted that various users making a multiple criteria analysis of the same alternatives often get diverse results. This may be due to the diversity of the overall aims and financial positions of the cities. Therefore, the initial data provided by various users for calculating the sustainable urban development project differ and consequently lead to various final results.

The character of the objective's choice for the most efficient variant is largely dependent on all available information. It should also be noted that the quantitative information is objective. The actual sustainable urban development alternatives have real costs. The values of the qualitative criteria are usually rather subjective though the application of an expert's methods contributes to their objectivity.

The tables assessing sustainable urban development solutions are used as a basis for working out the matrices of decision-making. These matrices, along with the use of a modelbase and models, make it possible to perform a multiple criteria analysis of alternative sustainable urban development projects, resulting in the selection of the most beneficial variants.

\subsection{Research Methods Model-Base}

In order effectively analyse database of best practice of sustainable urban development and to prepare recommendations for countries under consideration, it is essential to find the best research methods and analysis tools. The aim was to direct the research methods and analysis tools for assessing and implementing the goals of sustainable urban development.

Many decision making models and methods (multicriteria model [Nijkamp], a cost-benefit appraisal [Gallez], input-output analysis [Ferng], forecasting, quantitative and qualitative models and methods [Rotmans] have been developed in the world for solving the above and other problems.

The efficiency of a sustainable urban development variant is often determined by taking into account 
many factors. These factors include an account of the economic, institutional, environment, cultural, education, political, legal, social, management, technical, technological and other factors. The model-base of a decision support system should include models that enable a decision-maker to do a comprehensive analysis of the available variants and to make a proper choice.

Since the analysis of sustainable urban development is usually performed by taking into account various factors, a model-base should include models which will enable a decisionmaker to carry out a comprehensive analysis of the available variants and make a proper choice. The following multiple criteria analysis methods and models as developed by the authors [Kaklauskas] are used by the SUD-DSS in the analysis of the sustainable urban development alternatives:

- A new method and model of complex determination of the weight of the criteria taking into account their quantitative and qualitative characteristics was developed. This method allows one to calculate and coordinate the weights of the quantitative and qualitative criteria according to the above characteristics.

- A new method and model of multiple criteria complex proportional evaluation of projects enabling the user to obtain a reduced criterion determining the complex (overall) efficiency of the project was suggested. This generalized criterion is directly proportional to the relative effect of the values and weights of the considered criteria, on the efficiency of the project.

- In order to find what price will make a valuated project competitive on the market a method and model for determining the utility degree (see Fig. 2) and market value of projects based on the complex analysis of all their benefits and drawbacks was suggested. According to this method the project's utility degree and the market value of a project being estimated are directly proportional to the system of the criteria and adequately describe them, the values and weights of these criteria.

- A new method and model of multiple criteria multi-variant design of a project's life cycle enabling the user to make computer-aided design of up to 100,000 alternative project versions was developed. Any project's life cycle variant obtained in this way is based on quantitative and conceptual information [Zavadskas].

According to the user's needs, various models may be provided by a model management system. When a certain model (i.e. search for sustainable urban development alternatives) is used the results obtained become the initial data for some other models (i.e. a model for multiple criteria analysis and setting the priorities). The results of the latter, in turn, may be taken as the initial data for some other models (i.e. determination of utility degree). The management system of the model base allows a person to modify the available models, eliminate those that are no longer needed and add some new models that are linked to the existing ones.

This decision support system includes models enabling a decision maker to make a comprehensive analysis of the sustainable urban development variants that are available and then make the best choice for cities under consideration.

The more alternative versions investigated before making a final decision, the greater the possibility to achieve a more rational end result. Basing oneself on a sustainable urban development database in one's possession and the decision support system, it is possible to perform a multiple criteria analysis of sustainable urban development components and select the most efficient versions for the particular country. Strengths and weaknesses of the investigated sustainable urban development components also can be given in the analysis. Facts as to why and to what degree one version is better than another also can be established.

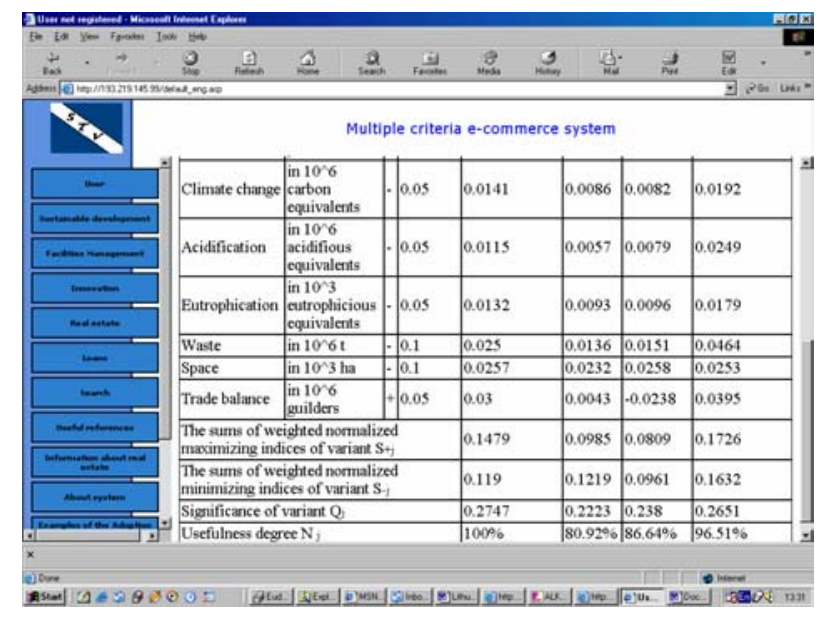

Figure 2. Integrated assessment for sustainable economic structures

In this way, the decision support system enables 
the decision maker to receive various conceptual and quantitative information on sustainable urban development from a database and a model-base which allows him/her to analyse the sustainable urban development components and to end with an efficient solution.

Different countries have their specific needs as well as political, economical, social, technological, environmental, legal/regulatory and education situations. Therefore, every time countries use the sustainable urban development database they may make corrections to the database according to the aims to be achieved and the available situation. For example, a certain city considers economic sustainability to be more important than social sustainability, while other cities may be of the opposite opinion. The city striving to express its attitude towards these issues numerically may ascribe various significance values to them, which will eventually affect the general estimation of a sustainable urban development. Though this assessment may seem biased and even quite subjective, the solution finally made may exactly meet the requirements, aims and affordability of the city under consideration.

In this way we have a great number of potential stakeholders (urban developers, investors, providers, regulators, users, experts, etc.) of sustainable urban development which can employ of envisaged main deliverables.

\subsection{Formation of Recommendations to Improve the Sustainable Urban Development in Lithuanian by Using SUD-DSS}

The formation of recommendations to improve the level of efficiency of sustainable urban development in Lithuanian was included the following stages:

1. Identification and description of the present state of sustainable urban development in Lithuania and in developed countries:

a) The formation of a system of criteria, characterizing the present state of sustainable urban development as determined by using experts methods;

b) A description of the present state of Lithuanian and developed countries of sustainable urban development is given in a conceptual (textual, graphical, numerical, etc.) form and based on the above criteria system.

2. Comparison and contrasting of Lithuanian sustainable urban development with those of developed countries (see Table 1):

a) Identification of the development trends and general regularities of the sustainable urban development in developed countries;

b) Identification of the differences between sustainable urban development in Lithuania and in developed countries;

c) Determination of the pluses and minuses of these differences for Lithuania today and in the future;

d) Determination an efficient environment for Lithuanian sustainable urban development based on Lithuanian conditions.

3. Development of an initial database of best practice of sustainable urban development.

4. Determination of effective solutions of sustainable urban development in Lithuania. The SUD-DSS's model base allows for interested parties to identify areas where the Lithuanian situation is rational, average or is quite bad comparing with levels attained by developed countries. The data obtained, using this model base, can identify rational sustainable urban development trends in Lithuania.

5. Formation of recommendations to improve the level of efficiency of sustainable urban development in Lithuanian.

Table 1. Comparison and contrasting of the sustainable urban development efficiency factors in Lithuania and developed countries

Stage 1. Identification of the development trends and general regularities of the sustainable urban development in developed countries

\begin{tabular}{|c|c|c|c|c|c|c|}
\hline $\begin{array}{c}\text { Countries } \\
\text { considered }\end{array}$ & \multicolumn{6}{|c|}{$\begin{array}{c}\text { Information pertinent to development trends and } \\
\text { general regularities of the sustainable urban } \\
\text { development }\end{array}$} \\
\cline { 2 - 7 } & $\begin{array}{c}\text { Quality of } \\
\text { life }\end{array}$ & $\begin{array}{c}\text { Environ- } \\
\text { ment }\end{array}$ & $\ldots$ & $\begin{array}{c}\text { Safety, } \\
\text { security }\end{array}$ & $\ldots$ & $\begin{array}{c}\text { Decision } \\
\text { making }\end{array}$ \\
\hline UK & $A_{11}$ & $A_{12}$ & $\ldots$ & $A_{1 j}$ & $\ldots$ & $A_{1 n}$ \\
$\ldots$ & $\ldots$ & $\ldots$ & $\ldots$ & $\ldots$ & $\ldots$ & $\ldots$ \\
Sweden & $A_{i 1}$ & $A_{i 2}$ & $\ldots$ & $A_{i j}$ & $\ldots$ & $A_{i n}$ \\
$\ldots$ & $\ldots$ & $\ldots$ & $\ldots$ & $\ldots$ & $\ldots$ & $\ldots$ \\
USA & $A_{t 1}$ & $A_{t 2}$ & $\ldots$ & $A_{t j}$ & $\ldots$ & $A_{t n}$ \\
\hline
\end{tabular}

Stage 2. Identification of differences between sustainable urban development in Lithuania and developed countries

\begin{tabular}{|c|c|c|c|c|c|c|}
\hline \multirow[t]{2}{*}{$\begin{array}{l}\text { Countries } \\
\text { considered }\end{array}$} & \multicolumn{6}{|c|}{$\begin{array}{c}\text { Identification of differences between sustainable urban } \\
\text { development in Lithuania and developed countries }\end{array}$} \\
\hline & \begin{tabular}{|c|c|} 
Quality of \\
life
\end{tabular} & $\begin{array}{c}\begin{array}{c}\text { Environ- } \\
\text { ment }\end{array} \\
\end{array}$ & $\ldots$ & $\begin{array}{l}\text { Safety, } \\
\text { security }\end{array}$ & $\ldots$ & $\begin{array}{c}\text { Decision } \\
\text { making }\end{array}$ \\
\hline UK & $D_{11}$ & $D_{12}$ & ... & $D_{1 j}$ & $\ldots$ & $D_{1 n}$ \\
\hline Sweden & $D_{i 1}$ & $D_{i 2}$ &. & $D_{i j}$ &. & $D_{i n}$ \\
\hline & & & $\cdots$ & & 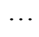 & \\
\hline USA & $D_{t 1}$ & $D_{t 2}$ & & $\underline{D_{t j}}$ & & $D_{t n}$ \\
\hline
\end{tabular}


Stage 3. Determination of pluses and minuses of differences between Lithuanian and developed countries sustainable urban development today and in the future

\begin{tabular}{|c|c|c|c|c|c|c|}
\hline $\begin{array}{c}\text { Countries } \\
\text { considered }\end{array}$ & \multicolumn{6}{|c|}{$\begin{array}{c}\text { Determination of pluses and minuses of differences } \\
\text { between Lithuanian and developed countries } \\
\text { sustainable urban development today and in the future }\end{array}$} \\
\cline { 2 - 7 } & $\begin{array}{c}\text { Quality of } \\
\text { life }\end{array}$ & $\begin{array}{c}\text { Environ- } \\
\text { ment }\end{array}$ & $\ldots$ & $\begin{array}{c}\text { Safety, } \\
\text { security }\end{array}$ & $\ldots$ & $\begin{array}{c}\text { Decision } \\
\text { making }\end{array}$ \\
\hline UK & $P_{11}$ & $P_{12}$ & $\ldots$ & $P_{1 j}$ & $\ldots$ & $P_{1 n}$ \\
$\ldots$ & $\ldots$ & $\ldots$ & $\ldots$ & $\ldots$ & $\ldots$ & $\ldots$ \\
Sweden & $P_{i 1}$ & $P_{i 2}$ & $\ldots$ & $P_{i j}$ & $\ldots$ & $P_{i n}$ \\
$\ldots$ & $\ldots$ & $\ldots$ & $\ldots$ & $\ldots$ & $\ldots$ & $\ldots$ \\
USA & $P_{t 1}$ & $P_{t 2}$ & $\ldots$ & $P_{t j}$ & $\ldots$ & $P_{t n}$ \\
\hline
\end{tabular}

Stage 4. Determination of an efficient environment for Lithuanian sustainable urban development based on Lithuanian conditions

\begin{tabular}{|c|c|c|c|c|c|c|}
\hline $\begin{array}{c}\text { Countries } \\
\text { considered }\end{array}$ & \multicolumn{6}{|c|}{$\begin{array}{c}\text { Determination of an efficient environment for } \\
\text { Lithuanian sustainable urban development based on } \\
\text { Lithuanian conditions }\end{array}$} \\
\cline { 2 - 7 } & $\begin{array}{c}\text { Quality of } \\
\text { life }\end{array}$ & $\begin{array}{c}\text { Environ- } \\
\text { ment }\end{array}$ & $\ldots$ & $\begin{array}{c}\text { Safety, } \\
\text { security }\end{array}$ & $\ldots$ & $\begin{array}{c}\text { Decision } \\
\text { making }\end{array}$ \\
\hline UK & $E_{11}$ & $E_{12}$ & $\ldots$ & $E_{1 j}$ & $\ldots$ & $E_{1 n}$ \\
Denmark & $E_{21}$ & $E_{22}$ & $\ldots$ & $E_{2 j}$ & $\ldots$ & $E_{2 n}$ \\
$\ldots$ & $\ldots$ & $\ldots$ & $\ldots$ & $\ldots$ & $\ldots$ & $\ldots$ \\
Sweden & $E_{i 1}$ & $E_{i 2}$ & $\ldots$ & $E_{i j}$ & $\ldots$ & $E_{i n}$ \\
$\ldots$ & $\ldots$ & $\ldots$ & $\ldots$ & $\ldots$ & $\ldots$ & $\ldots$ \\
USA & $E_{t 1}$ & $E_{t 2}$ & $\ldots$ & $E_{t j}$ & $\ldots$ & $E_{t n}$ \\
\hline
\end{tabular}

\section{CONCLUSIONS}

A variety of sustainable urban development automation systems have been analyzed to determine which processes are being supported on-line. The results of this study provide a useful insight into creating ones own Sustainable Urban Development Decision Support System (SUDDSS). SUD-DSS differs from others in the use of new multiple criteria analysis methods as were developed by the authors. The database of a sustainable urban development was developed providing a comprehensive assessment of alternative versions from the economic, institutional, environment, cultural, education, political, legal, social, management, technical, technological and other perspectives. Based on the above complex databases, the developed SUDDSS enables the user to analyse alternatives quantitatively and conceptually.

\section{REFERENCES}

[Buch] Buch, A. M., Mazumdar, H. S. and Pandey, P. C. (1993) Application of artificial neural networks in hydrological modelling - a case study of run-off simulation of Himalayan glacier basin. Presented at International Joint Conference on Neural Networks, Nagoya, Japan.

[Cote] Cote, M., Grandjean, B.P.A., Lessard, P. and Thibault, J., 1995. Dynamic modelling of the activated sludge process: improving prediction using neural networks. Water Research 294 , pp. 995-1004.
[Ferng] J. J. Ferng. Toward a scenario analysis framework for energy footprints. Ecological Economics. Volume 40, Issue 1, January 2002, Pages 53-69.

[Furuta] Furuta, H., Tonegawa, T. and Watanabe, E., 1992. Application of neural computing to aesthetic design of dam structures. In: Proceedings of the 2nd International Conference of Fuzzy Logic and Neural Networks (IIZUKA'92) Vol. 2, pp. 851-854.

[Gallez] C. Gallez. Indicators for comparing prospective scenarios Can we broaden the urban travel debate? Recherce - Transports - Securite. 2000.

[Ichikawa] Ichikawa, R., Nishimura, K., Kunugi, M., Shimada, K., Shimakura, Y.H., Fujisawa, Y. and Matsunoki, Y., 1992. Auto-tuning method of fuzzy memberships functions using neural network learning algorithm: application to water flow forecasting for reservoir. In: Proceedings of the 2nd International Conference of Fuzzy Logic and Neural Networks (IIZUKA'92) Vol. 2, pp. 894898.

[Kaklauskas] A.Kaklauskas, E.Zavadskas. Web-based decision support. - V.: Technika. - 2002. - 292 p.

[Khanna] P. Khanna, P. R. Babu, M. S. George. Carryingcapacity as a basis for sustainable development. A case study of National Capital Region in India. Progress in Planning. Volume 52, Issue 2, August 1999, Pages 101-163.

[Nijkamp] P. Nijkamp, Ron Vreeker. Sustainability assessment of development scenarios: methodology and application to Thailand. Ecological Economics. Volume 33, Issue 1, April 2000, Pages 7-27.

[Onishi] A. Onishi. FUGI global modeling system (FGMS200). Integrated global model for sustainable development. Journal of Policy Modeling. Volume 24, Issue 6, October 2002, Pages 561-590

[Rotmans] J. Rotmans, M. Asselt, C. Anastasi, S. Greeuw, J. Mellors, S. Peters, D. Rothman, N. Rijkens.Visions for a sustainable Europe. Futures. Volume 32, Issue 9-10, November 2000, Pages 809-831.

[Rylatt] M. Rylatt, S. Gadsden, K. Lomas. GIS-based decision support for solar energy planning in urban environments. Computers, Environment and Urban Systems. Volume 25, Issue 6, November 2001, Pages 579-603.

[Yuan] Yuan, J.L. and T.I, Fine., 1993. Forecasting demand for electric power. In: Cewan, J.D. and Giles, C.L., Editors, 1993. Advances in Information Systems Vol. 5, Moregan Kanffman, San Matteo, pp. 739-746.

[Zavadskas] E.Zavadskas, L.Simanauskas, A.Kaklauskas. Decision support systems in construction. - V.: Technika. 1998. - $205 \mathrm{p}$.

[1] http://sun2.lib.uci.edu/ martindale/RefCalculators.html

[2] http://www.eere.energy.gov/buildings/tools_directory/subject.html

[3] http://www.census.gov/ipc/www/rup.html 